\title{
Noninvasive screening for intracranial hypertension in children with acute, severe traumatic brain injury
}

\author{
Nicole F. O'Brien, MD, ${ }^{1}$ Tensing Maa, MD, ${ }^{1}$ and Karin Reuter-Rice, PhD, NP, FCCM ${ }^{2}$ \\ 1Division of Critical Care Medicine, Department of Pediatrics, Nationwide Children's Hospital, The Ohio State University, \\ Columbus, Ohio; and ${ }^{2}$ School of Nursing, School of Medicine, Department of Pediatrics, Duke University, Durham, North \\ Carolina
}

OBJECT The aim of this study was to determine the relationship between transcranial Doppler (TCD) derived pulsatility index (PI), end diastolic flow velocity (Vd), and intracranial pressure (ICP). The subjects in this study were 36 children admitted after severe traumatic brain injury (TBI) (postresuscitation Glasgow Coma Scale $\leq 8$ ) undergoing invasive ICP monitoring.

METHODS Subjects underwent a total of 148 TCD studies. TCD measurements of systolic flow velocity (Vs), Vd, and mean flow velocity $(\mathrm{Vm})$ were performed on the middle cerebral artery (MCA) ipsilateral to the ICP monitor. The PI was calculated by the TCD software (Vs-Vd/Vm). ICP registrations were made in parallel with TCD measurements.

RESULTS Using a PI threshold of 1.3 , postinjury Day 0-1 PI had $100 \%$ sensitivity and $82 \%$ specificity at predicting an $I C P \geq 20 \mathrm{~mm} \mathrm{Hg}(n=8)$. During this time frame, a moderately strong relationship was observed between the MCA PI and actual ICP $(r=0.611, p=0.01)$. When using a threshold of $<25 \mathrm{~cm} / \mathrm{sec}$, postinjury Day $0-1 \mathrm{Vd}$ had a $56 \%$ sensitivity to predict an ICP $\geq 20 \mathrm{~mm} \mathrm{Hg}$. Beyond the initial 24 hours from injury, the sensitivity of an MCA PI of 1.3 to detect an ICP $\geq 20 \mathrm{~mm} \mathrm{Hg}$ was $47 \%$, and a weak relationship between actual ICP values and MCA PI $(r=0.376, p=0.01)$ and MCA Vd $(r=-0.284, p=0.01)$ was found.

CONCLUSIONS Postinjury Day 0-1 MCA PI > 1.3 has good sensitivity and specificity at predicting an ICP $\geq 20 \mathrm{~mm} \mathrm{Hg}$. In those children with TBI who initially do not meet clear criteria for invasive ICP monitoring but who are at risk for development of intracranial hypertension, TCD may be used as a noninvasive tool to screen for the development of elevated ICP in the first 24 hours following injury.

http://thejns.org/doi/abs/10.3171/2015.3.PEDS14521

KEY WORDS intracranial pressure; traumatic brain injury; transcranial Doppler ultrasound; pulsatility index; end diastolic flow velocity; intracranial hypertension; pediatrics; trauma

$\mathrm{T}$ Raumatic brain injury (TBI) is a major cause of death and disability in children worldwide. Each year in the United States, 473,947 children visit the emergency department due to head trauma. Of these, 35,000 are hospitalized and 2,100 die as a direct result of their injury. ${ }^{10,12}$ In survivors, behavioral issues, neurocognitive deficits, and motor disabilities are extremely common long-term problems.

During the acute phase of management of these children, morbidity and mortality is impacted by stressors such as hypoxia, hypotension, and increased intracranial pressure (ICP). Thus, treatment goals aim to reduce these factors that result in worsened brain injury. Current management guidelines recommend considering the use of ICP monitoring to guide therapy for infants, children, and adolescents with severe TBI (Glasgow Coma Scale [GCS] score $\leq 8) .{ }^{18}$ However, direct ICP measurement is an invasive surgical technique with potential serious complications such as hemorrhage and infection, and risk to benefit ratio of placement always needs to be considered. .,6,17 $^{-17}$ There is a subset of patients who do not meet guideline recommendations for ICP monitoring but who are at risk for the development of intracranial hypertension, and in whom serial neurological exams to detect neurological

ABBREVIATIONS GCS = Glasgow Coma Scale; ICP = intracranial pressure; $M C A=$ middle cerebral artery; $\mathrm{PI}=$ pulsatility index; $\mathrm{TBI}=$ traumatic brain injury; $\mathrm{TCD}=$ transcranial Doppler; $\mathrm{Vd}=$ diastolic flow velocity; $\mathrm{Vm}=$ mean flow velocity; $\mathrm{Vs}=$ systolic flow velocity

SUBMITTED October 4, 2014. ACCEPTED March 23, 2015.

INCLUDE WHEN CITING Published online July 3, 2015; DOI: 10.3171/2015.3.PEDS14521.

DISCLOSURE This work was supported by the Intramural Funding Program Nationwide Children's Hospital. 
deterioration are precluded (children sedated and mechanically ventilated for associated traumatic injuries). Therefore, a simple, noninvasive way to identify which of these patients is developing intracranial hypertension and in whom ICP monitoring should take place is desirable. There are also some patients with severe TBI who would benefit from ICP-directed therapy but in whom invasive ICP monitoring is contraindicated (severe coagulopathy) or not available (resource-poor settings). Therefore, identifying a noninvasive, simple means by which pressure changes over time can be accurately and reliably monitored is extremely important.

Transcranial Doppler (TCD) ultrasound is noninvasive and portable, and has been used to assess cerebral hemodynamics in a variety of clinical settings. ${ }^{1,2,14}$ It has been shown that as ICP rises, typical changes in cerebral blood flow velocities can be measured by TCD ${ }^{9,15}$ Several studies have suggested that TCD-derived end diastolic flow velocity (Vd) and pulsatility index (PI) are useful as noninvasive estimates of ICP in adults with TBI. 7,8,16,19,20,29,30 There are very limited and opposing data on the utility of TCD-derived Vd and PI to noninvasively screen for intracranial hypertension and to follow ICP over time in children with TBI. ${ }^{11,13,21}$ Given these conflicting reports in children, we designed this prospective, observational trial to further evaluate the relationship between PI, end $\mathrm{Vd}$, and ICP in infants, children, and adolescents with severe TBI. We hypothesized that TCD-derived parameters would be useful as a noninvasive screening tool to detect elevated ICP and could be used longitudinally to noninvasively estimate ICP in this patient population.

\section{Methods \\ Patients}

This was a prospective, observational trial involving 36 children (age 0-17 years) admitted to the pediatric intensive care unit with a diagnosis of severe TBI (postresuscitation GCS score $\leq 8$ ) who had an ICP monitor in place (external ventricular drain or parenchymal monitor, Camino or Licox, Integra Neurosciences). The type of intraparenchymal monitor that was used was left to the discretion of the neurosurgical attending physician. Demographic data such as age, sex, GCS score, and mechanism of injury were recorded for all participants. This study was approved by the institutional review board, and consent was obtained prior to participation for all subjects.

\section{TCD Examinations}

Daily TCD measurements were conducted transtemporally using a commercially available $2-\mathrm{MHz}$ transducer (Sonara Digital TCD, CareFusion). The quality of the data obtained by TCD is highly influenced by operatordependent factors. All TCD evaluations were performed by 3 individuals who are trained and experienced in TCD practices. In training sessions prior to the study, a coefficient of variation $<10 \%$ for each study measurement between sonographers was demonstrated. All initial TCD evaluations were performed within 24 hours of the injury. TCD measurements were routinely performed on the middle cerebral artery (MCA) ipsilateral to the ICP moni- tor. The depth and angle of insonation giving the highest mean flow velocity $(\mathrm{Vm})$ in the MCA was always chosen. Recorded parameters included peak systolic flow velocity (Vs), Vm, and Vd. The PI was calculated by the TCD unit according to the method described by Gosling. ${ }^{13}$ Based on previous studies that successfully used TCD-derived parameters to predict intracranial hypertension in children following TBI, threshold values of $\mathrm{Vd}<25 \mathrm{~cm} / \mathrm{sec}$ or PI $>1.3$ were used in this protocol. ${ }^{21} \mathrm{TCD}$ recordings were included in the study as long as arterial carbon dioxide tension was between 30-45 $\mathrm{mm} \mathrm{Hg}$ and hemodynamics were stable with blood pressure within the normal range for age. TCD studies were excluded if a reversal of flow pattern consistent with brain death was observed or if the flow velocities met diagnostic criteria for vasospasm. Simultaneous measurement of the ICP was taken at the time of the TCD study. Due to overhead monitoring practices of ICP, sonographers were not blinded to ICP measurements at the time of the TCD examination.

\section{Statistical Analysis}

Descriptive values were expressed as frequencies for dichotomous variables and as mean $\pm \mathrm{SD}$ or median (minimum-maximum value) for continuous variables. Categorical variables were compared between groups using Fisher's exact test. For comparison of continuous variables between groups, independent sample t-test or Wilcoxon rank-sum test was used. Pearson's correlation coefficient was used to test the general correlation between Vd, PI, and ICP. Examination of binary values for Vd, PI, and ICP was also performed. A threshold of $\mathrm{Vd} \leq 25 \mathrm{~cm} / \mathrm{sec}$ and a PI threshold of 1.3 were set based on previous studies..$^{9,13,21}$ A threshold of $20 \mathrm{~mm} \mathrm{Hg}$ was set for the ICP as this is the recommended threshold for initiation of ICP treatment in children with TBI. ${ }^{18}$ Data analysis was performed using SPSS version 17 (SPSS Inc.). A p value $\leq 0.05$ was considered significant.

\section{Results}

A total of 148 TCD recordings (36 postinjury Day 0-1, 112 subsequent) were performed on 36 children with severe TBI. Mean age of the cohort was 6.6 years $( \pm 4.8$ years, range 7 months -15 years). Mean GCS score was 5.8 \pm 2 (range $3-8$ ). The cohort included 21 boys and 15 girls. Mechanism of injuries for these patients included motor vehicle accidents $(n=13)$, falls $(n=4)$, pedestrian versus automobile $(\mathrm{n}=9)$, abusive head trauma $(\mathrm{n}=7)$, and other $(\mathrm{n}=3)$. Thirteen patients $(36 \%)$ underwent primary decompressive craniotomy for mass lesion within the first 24 hours of admission. The mean time from admission to the first TCD assessment was $12 \pm 5$ hours (range 6-23 hours).

On initial evaluations on postinjury Day $0-1$ (within 24 hours of injury), ICP was $\geq 20 \mathrm{~mm} \mathrm{Hg}$ in 8 patients (22.2\%). Mean ICP for these patients was $35 \pm 14 \mathrm{~mm} \mathrm{Hg}$ (range $21-60 \mathrm{~mm} \mathrm{Hg}$ ). ICP measurements on postinjury Day 0-1 were $<20 \mathrm{~mm} \mathrm{Hg} 77.8 \%$ of the time. Mean ICP for this group was $10 \pm 4.6 \mathrm{~mm} \mathrm{Hg}$ (range 3-19 mm Hg).

The mean PI for the children with an initial ICP $\geq 20$ $\mathrm{mm} \mathrm{Hg}$ was $1.9 \pm 0.61$ (range 1.3-3.1). The mean PI for the children with an initial ICP $<20 \mathrm{~mm} \mathrm{Hg}$ was $0.95 \pm$ 
0.35 (range $0.35-1.6, \mathrm{p}=0.03$ ) (Table 1). Using a threshold of 1.3 , the initial PI had $100 \%$ sensitivity and $82 \%$ specificity at predicting an ICP $\geq 20 \mathrm{~mm} \mathrm{Hg}(\mathrm{n}=8)$ (Table 2). A moderately strong relationship was observed between MCA PI and ICP $(r=0.611, p=0.01)$ on postinjury Day 0-1 (Fig. 1).

Mean Vd when postinjury Day 0-1 ICP was $\geq 20 \mathrm{~mm}$ $\mathrm{Hg}$ was $21 \pm 18 \mathrm{~cm} / \mathrm{sec}$ (range $3-61 \mathrm{~cm} / \mathrm{sec}$ ), and mean Vd when initial ICP was $<20 \mathrm{~mm} \mathrm{Hg}$ was $62 \pm 27 \mathrm{~cm} / \mathrm{sec}$ (range $16-129 \mathrm{~cm} / \mathrm{sec}, \mathrm{p}=0.001$ ) (Table 1). Using an initial Vd threshold of $<25 \mathrm{~cm} / \mathrm{sec}$, the sensitivity to predict an ICP $\geq 20 \mathrm{~mm} \mathrm{Hg}$ was $56 \%$ (data not shown). Postinjury Day 0-1 MCA Vd correlated less well than PI with actual $\operatorname{ICP}(\mathrm{r}=-0.484, \mathrm{p}=0.01)$ (Fig. 2).

Postinjury Day 2 ( $>24$ hours from injury) or later ICP measurements were $\geq 20 \mathrm{~mm} \mathrm{Hg} 33$ times (29\%) and < $20 \mathrm{~mm} \mathrm{Hg} 79$ times (71\%). In patients with intracranial hypertension (ICP $\geq 20 \mathrm{~mm} \mathrm{Hg}$ ), the mean ICP was $31 \pm$ $11 \mathrm{~mm} \mathrm{Hg}$ (range 21-67 mm Hg). The mean ICP for the children without intracranial hypertension was $10 \pm 4 \mathrm{~mm}$ $\mathrm{Hg}$ (range 2-18 $\mathrm{mm} \mathrm{Hg}$ ).

The mean PI for the children with ICP measurements $\geq$ $20 \mathrm{~mm} \mathrm{Hg}$ outside postinjury Day $0-1$ was $1.1 \pm 0.4$ (range $0.5-2)$. The mean PI for the children with an ICP $<20$ $\mathrm{mm} \mathrm{Hg}$ outside postinjury Day $0-1$ was $0.99 \pm 0.3$ (range $0.5-1.7, p=0.3$ ). Outside postinjury Day $0-1$, the sensitivity and specificity of a MCA PI threshold of 1.3 to predict intracranial hypertension was $47 \%$ and $84 \%$, respectively (data not shown). After postinjury Day 0-1, a weak relationship between ICP values and MCA PI was found $(r=$ 0.376, $\mathrm{p}=0.01$ ) (Fig. 3).

On these subsequent measurements, mean $\mathrm{Vd}$ when ICP was $\geq 20 \mathrm{~mm} \mathrm{Hg}$ was $42 \pm 26 \mathrm{~cm} / \mathrm{sec}$ (range 22-80 $\mathrm{cm} / \mathrm{sec}$ ) and mean Vd when ICP was $<20 \mathrm{~mm} \mathrm{Hg}$ was 56 $\pm 24 \mathrm{~cm} / \mathrm{sec}$ (range $37-120 \mathrm{~cm} / \mathrm{sec}, \mathrm{p}=0.06$ ) (Table 1 ). The sensitivity and specificity of an MCA Vd $<25 \mathrm{~cm} / \mathrm{sec}$ to detect an ICP $\geq 20 \mathrm{~mm} \mathrm{Hg}$ outside postinjury Day $0-1$ was $63 \%$ and $12 \%$, respectively (data not shown). Additionally, the relationship between ICP and MCA Vd weakened further than what was seen in the early postinjury phase $(r=-0.284, p=0.01$, data not shown).

Due to concerns that an open fontanelle may influence the typical TCD waveform pattern of ICP elevation, data from infants and children $<1$ year of age $(n=6)$ were removed and the analysis was repeated. No significant improvement in the relationship between PI and ICP outside of postinjury Day $0-1$ was found $(r=0.39, p=0.01$, data not shown). Due to similar concerns in those patients who underwent a decompressive craniotomy $(\mathrm{n}=13)$, PI and ICP values that were obtained following that procedure were also removed and the analysis was repeated. Again, no significant improvement in the relationship between PI and ICP outside of postinjury Day $0-1$ was seen $(r=0.35$, $\mathrm{p}=0.01$, data not shown).
TABLE 2. ICP and postinjury Day 0-1 MCA PI*

\begin{tabular}{ccc}
\hline MCA PI & ICP $<20 \mathrm{~mm} \mathrm{Hg}$ & ICP $\geq 20 \mathrm{~mm} \mathrm{Hg}$ \\
\hline$<1.3$ & 23 & 0 \\
$\geq 1.3$ & 5 & 8 \\
Total & 28 & 8 \\
\hline
\end{tabular}

* Values are numbers of patients. Initial TCD had a sensitivity of $100 \%$ and a specificity of $82 \%$ to predict ICP $\geq 20 \mathrm{~mm} \mathrm{Hg}$ with an MCA PI threshold of 1.3 .

\section{Discussion}

In children with severe TBI, knowledge of ICP is essential to help guide treatment. However, direct ICP monitoring is invasive, associated with complications, and not always possible based on clinical contraindications. Thus, finding an alternative means by which to accurately assess ICP and determine if invasive monitoring should be pursued is desirable.

TCD ultrasound is portable and noninvasive, and has been used to evaluate the cerebral hemodynamics of critically ill adults and children. ${ }^{3,4,12,14,21,24,26-28}$ The TCD probe is placed over different "acoustic windows" that are specific areas of the skull where the cranial bone is thin. Most commonly, the temporal window is used to visualize the MCA. The TCD ultrasound probe emits an ultrasonic beam of 2-MHz frequency. The beam is reflected off the erythrocytes within the artery being evaluated, is received by the ultrasound probe, and is converted to an electrical signal. This information is then processed to obtain a waveform that represents blood flow velocity through the insonated vessel. By taking repeated measurements, advancing by small increments along the entire length of each cerebral vessel, flow velocities throughout the cerebral circulation can be readily determined.

Typical TCD waveform changes have been described during various pathophysiological states. In a feline model of progressive intracranial hypertension, Nagai and colleagues demonstrated that incremental increases in ICP produced typical changes in TCD waveforms. ${ }^{23} \mathrm{An}$ increase in ICP brought about a more rapid reduction in flow velocity in the diastolic phase than in the systolic phase. This resulted in a pronounced difference between peak systole and the end of diastole. The PI is a value that is calculated by the TCD software according to the following equation: (peak Vs - end Vd)/timed Vm). Therefore, not only was there a progressive reduction in the measured end Vd but also a progressive increase in PI as ICP rose. These findings suggest elevated PIs and low end diastolic volumes may correlate with measured ICP.

Indeed, studies in adults with TBI have shown a favorable correlation between ICP and TCD-derived PI and Vd. ${ }^{8,9,16,20,30}$ Bellner et al., in a study involving 81 patients with mixed etiologies of neurological disease, found a strong relationship between PI and the ICP $(r=0.938, p$

TABLE 1. Mean PI and end Vd values obtained in children with and without intracranial hypertension

\begin{tabular}{ccccccc}
\hline Parameter & $\begin{array}{c}\text { Postinjury Day 0-1 } \\
\text { ICP }<20 \mathrm{~mm} \mathrm{Hg}\end{array}$ & $\begin{array}{c}\text { Postinjury Day 0-1 } \\
\mathrm{ICP} \geq 20 \mathrm{~mm} \mathrm{Hg}\end{array}$ & $\mathrm{p} \mathrm{Value}$ & $\begin{array}{c}\text { Subsequent ICP }<20 \\
\mathrm{~mm} \mathrm{Hg}\end{array}$ & $\begin{array}{c}\text { Subsequent ICP } \geq 20 \\
\mathrm{~mm} \mathrm{Hg}\end{array}$ & $p$ Value \\
\hline $\mathrm{PI}$ & $0.95 \pm 0.35$ & $1.9 \pm 0.61$ & 0.03 & $0.99 \pm 0.3$ & $1.1 \pm 0.4$ & 0.3 \\
\hline $\mathrm{Vd}$ & $62 \pm 27$ & $21 \pm 18$ & 0.001 & $56 \pm 24$ & $42 \pm 26$ & 0.06 \\
\hline
\end{tabular}




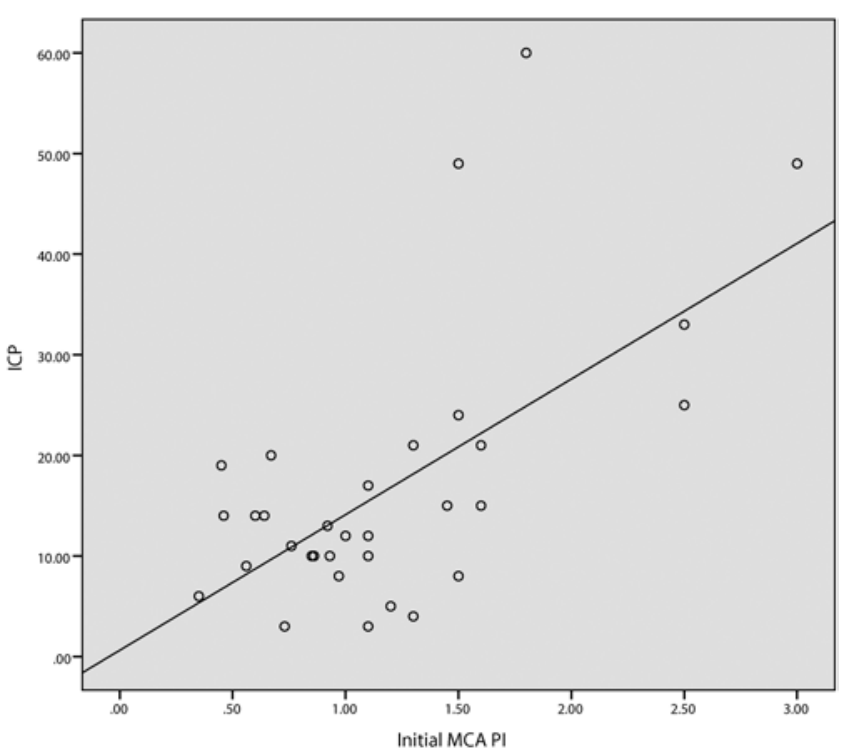

FIG. 1. Graph demonstrating relationship between ICP and the initial MCA PI. Correlation coefficient $0.611(p=0.01)$.

$<0.0001){ }^{7}$ Using the PI, this study found that an ICP $\geq$ $20 \mathrm{~mm} \mathrm{Hg}$ was predicted with a sensitivity of 0.89 and a specificity of 0.92 . Additionally, in a group of 41 patients who had suffered TBI, Chan et al. found that as ICP increased or mean arterial blood pressure decreased, there was a reduction in measured cerebral blood flow velocities with Vd falling more than Vs. ${ }^{8}$ This resulted in an increase in PI with good correlation between measured ICP and PI $(r=0.942, p<0.0001)$. However, findings from other studies in adults with neurological illness and injury are in direct contrast to these and suggest that TCD-derived parameters are clinically inadequate predictors of ICP. ${ }^{6,9,31}$

To date, there have only been 2 studies evaluating the use of TCD-derived parameters to predict ICP in children with TBI. ${ }^{13,21}$ Melo et al. retrospectively reviewed the TCD evaluations on 117 head injured children with ICP monitors in place. ${ }^{20}$ In this study, all studies were performed during the resuscitation phase within the first 20 minutes

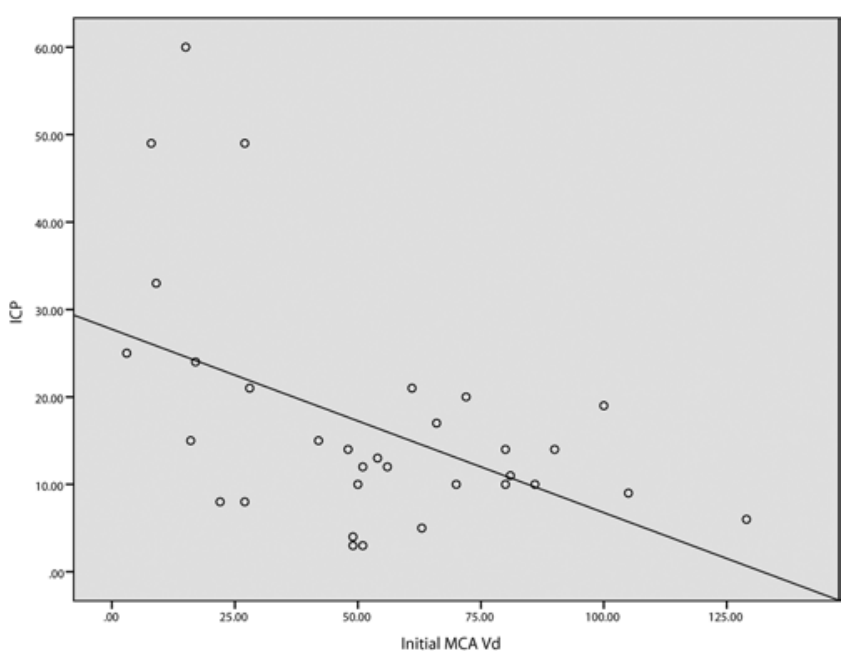

FIG. 2. Graph demonstrating relationship between ICP and the initial MCA end Vd. Correlation coefficient $-0.484(p=0.01)$.

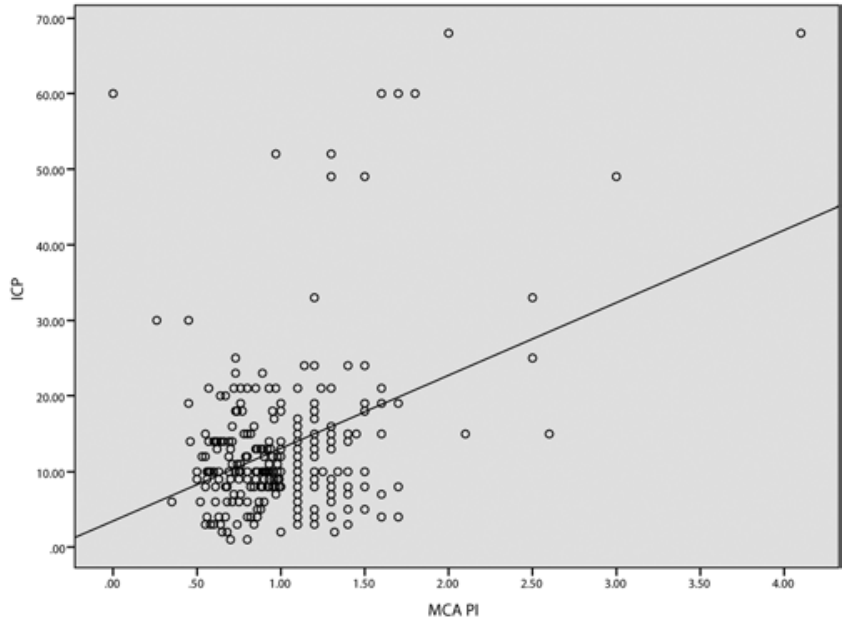

FIG. 3. Graph demonstrating relationship between ICP measurements taken outside postinjury Day $0-1$ and MCA PI. Correlation coefficient of $0.376(p=0.01)$.

of arrival to the treatment center. Using threshold values of $\mathrm{Vd}<25 \mathrm{~cm} / \mathrm{sec}$ or PI $>1.3$, TCD had a $94 \%$ sensitivity at predicting an initial ICP $\geq 20 \mathrm{~mm} \mathrm{Hg}$. Those authors concluded that TCD could be used as a first-line method to identify those children with elevated ICP in need of more invasive ICP monitoring. In a study involving 34 children with severe TBI, Figaji et al. performed 291 TCD recordings over the course of their intensive care unit stay. $.^{12} \mathrm{Me}-$ dian day of TCD testing for this study was Day 3 (range 1-10 days postinjury). Using a threshold of 1.2 for the PI, the sensitivity of detecting an ICP $\geq 20 \mathrm{~mm} \mathrm{Hg}$ was only $11.5 \%$. Only a weak relationship between MCA PI and ICP was discovered $(r=0.36, p=0.4)$. The authors, therefore, concluded that the PI is not a reliable guide to estimate the absolute ICP in pediatric patients with severe TBI.

Given the relative paucity of literature on this topic in pediatric patients, we performed the current prospective, observational study to further evaluate the utility of TCD-derived MCA PI and Vd to noninvasively determine ICP in children with TBI. In general, our findings show a weaker relationship between ICP and PI than what has been demonstrated in the majority of adult studies. ${ }^{8,9,16,20,30}$ The reasons for this difference are unclear but are likely related to the differences between adult and pediatric TBI in regards to pathology, brain tissue compliance, CSF pulsatility, and cerebrovascular control mechanisms..$^{22,25,30,32}$

The results of the 2 previous studies evaluating the utility of TCD-derived PI and Vd to noninvasively estimate ICP in pediatric patients who have suffered TBI appear to be in contrast to one another. ${ }^{13,21}$ However, it should be noted that the TCD evaluations in these 2 studies were performed at very different and distinct time points. In the Melo study, TCD data were obtained at an ultra-early time point in the emergency department. Figaji and colleagues performed TCD evaluations and simultaneous ICP measurements at later time points throughout the course of the management of the children (median day postinjury Day 3). In fact, our findings were consistent with both of these studies. When evaluating the correlation between postinjury Day 0-1 MCA PI measurement and ICP, we found 
a moderately strong relationship $(\mathrm{r}=0.611, \mathrm{p}=0.01)$. We also, when using a cutoff of 1.3 , found that the postinjury Day $0-1$ PI had $100 \%$ sensitivity and $82 \%$ specificity at predicting an ICP $\geq 20 \mathrm{~mm} \mathrm{Hg}$. These findings are very significant in that they suggest that within 24 hours of injury, TCD may be used as a noninvasive screening tool to detect those children with intracranial hypertension. Following current treatment guidelines, children with severe TBI and a GCS score $\leq 8$ will have an invasive ICP monitor placed based on their clinical status alone. However, there is a proportion of children who do not meet these guidelines (moderate TBI with GCS score of 9-12) who are at risk for neurological deterioration following trauma in whom reliable neurological exams are precluded due to sedation and mechanical ventilation for nonneurological injuries. The findings of this study suggest that TCD can be used in the initial critical 24 hours to detect which of these children has developed intracranial hypertension, and invasive ICP monitoring should be considered to guide management if they cannot be extubated or have sedation lifted.

It is important to note, however, that following this initial 24 hours postinjury, this relationship was lost in our study. TCD-derived parameters could no longer be used to reliably screen for intracranial hypertension or guide management in children with TBI beyond postinjury Day 1. The reasons for the loss of this relationship are not clear but may be related to known time-based changes in cerebral blood flow following TBI in children. Specifically, regional increases in blood flow related to hyperemia are known to occur following postinjury Day 1 in children., ${ }^{3,18}$ Hyperemia increases flow velocity measurements and could potentially obscure the impact of increased ICP on the TCD-derived parameters of Vd and PI.

Future pediatric studies with larger numbers of patients across various age groups should further evaluate the utility of TCD ultrasound to screen for intracranial hypertension. Future studies should also focus on delineating the time postinjury at which PI and Vd are no longer adequately sensitive to detect intracranial hypertension in children.

\section{Study Limitations}

Several potential limitations to our study exist. First, flow velocity patterns can be influenced by a number of factors such as mean arterial pressure, fever, partial pressure of carbon dioxide, hematocrit, and sedation. These factors were not controlled for in this study, so variability in them may have influenced measured TCD flow velocities and decreased the correlation between PI, Vd, and ICP. However, while each of these parameters is considered during TBI management, complete normalization of each of them while taking care of these patients is difficult. Therefore, some variability in these factors is to be expected in the management of these children, and a screening tool to evaluate for elevated ICP would need to be highly sensitive, even in the face of this variability.

Secondly, there were relatively few TCD examinations performed when the ICP $\geq 20 \mathrm{~mm} \mathrm{Hg}(\mathrm{n}=41,28 \%)$. A higher number of observations may have strengthened the relationship between PI and ICP and improved the util- ity of TCD at detecting intracranial hypertension outside postinjury Day 0-1. However, Bellner et al. found the best correlation occurred at lower ICPs. As ICP increased above $20 \mathrm{~mm} \mathrm{Hg}$ the correlation became less convincing.

Lastly, TCD measurements from a relatively large age range ( 7 months -15 years) were included in this study. This age range represents significant differences in typical mechanism of injury, in the physiological response to injury, and in normal baseline Vd. Ideally, large numbers of children within a narrow age range should be evaluated to determine if there is a certain subset of patients in whom TCD flow velocities cannot reliably be used at any point in time or in whom it could be used to noninvasively follow ICP beyond the initial phase.

\section{Conclusions}

Significant differences in postinjury Day 0-1 TCDderived PI and end Vd are seen in children with intracranial hypertension compared with children with normal ICP. Specifically, during this time frame, using a threshold MCA PI $>1.3$ an ICP $\geq 20 \mathrm{~mm} \mathrm{Hg}$ can be detected with excellent sensitivity and specificity by this noninvasive means. Subsequent PI measurements and end Vd outside the initial phase postinjury do not correlate well with actual ICP measurements and cannot be used to detect an ICP $\geq 20 \mathrm{~mm} \mathrm{Hg}$. We conclude that TCD-derived PI has significant clinical value when used as an early screening tool to determine children at risk for intracranial hypertension.

\section{References}

1. Aaslid R, Lindegaard KF, Sorteberg W, Nornes H: Cerebral autoregulation dynamics in humans. Stroke 20:45-52, 1989

2. Aaslid R, Markwalder TM, Nornes H: Noninvasive transcranial Doppler ultrasound recording of flow velocity in basal cerebral arteries. J Neurosurg 57:769-774, 1982

3. Adelson PD, Clyde B, Kochanek PM, Wisniewski SR, Marion DW, Yonas H: Cerebrovascular response in infants and young children following severe traumatic brain injury: a preliminary report. Pediatr Neurosurg 26:200-207, 1997

4. Adelson PD, Srinivas R, Chang Y, Bell M, Kochanek PM: Cerebrovascular response in children following severe traumatic brain injury. Childs Nerv Syst 27:1465-1476, 2011

5. Anderson RCE, Kan P, Klimo P, Brockmeyer DL, Walker ML, Kestle JR: Complications of intracranial pressure monitoring in children with head trauma. J Neurosurg 101 (1 Suppl):53-58, 2004

6. Behrens A, Lenfeldt N, Ambarki K, Malm J, Eklund A, Koskinen LO: Transcranial Doppler pulsatility index: not an accurate method to assess intracranial pressure. Neurosurgery 66:1050-1057, 2010

7. Bellner J, Romner B, Reinstrup P, Kristiansson KA, Ryding E, Brandt L: Transcranial Doppler sonography pulsatility index (PI) reflects intracranial pressure (ICP). Surg Neurol 62:45-51, 2004

8. Chan KH, Miller JD, Dearden NM, Andrews PJ, Midgley S: The effect of changes in cerebral perfusion pressure upon middle cerebral artery blood flow velocity and jugular bulb venous oxygen saturation after severe brain injury. J Neurosurg 77:55-61, 1992

9. de Riva N, Budohoski KP, Smielewski P, Kasprowicz M, Zweifel C, Steiner LA, et al: Transcranial Doppler pulsatility index: what it is and what it isn't. Neurocrit Care 17:58-66, 2012

10. Faul M, Xu L, Wald MM, Coronado VG: Traumatic Brain 
Injury in the United States: Emergency Department Visits, Hospitalizations, and Deaths 2002-2006. Atlanta: Centers for Disease Control and Prevention, National Center for Injury Prevention and Control, 2010

11. Figaji AA, Zwane E, Fieggen AG, Argent AC, Le Roux PD, Siesjo P, et al: Pressure autoregulation, intracranial pressure, and brain tissue oxygenation in children with severe traumatic brain injury. J Neurosurg Pediatr 4:420-428, 2009

12. Figaji AA, Zwane E, Fieggen AG, Siesjo P, Peter JC: Transcranial Doppler pulsatility index is not a reliable indicator of intracranial pressure in children with severe traumatic brain injury. Surg Neurol 72:389-394, 2009

13. Gosling RG, King DH: Arterial assessment by Doppler-shift ultrasound. Proc R Soc Med 67:447-449, 1974

14. Goutorbe PV, Bruder N, Cantais E, Leblanc PE, Pelissier D, Gouin F: Apport du duppler transcrânien (DTC) pour l'évaluation dela gravite des traumatismes crâniens à la phase precoce. Ann Fr Anesth Réanim 20 (Suppl 1):R451, 2001

15. Homburg AM, Jakobsen M, Enevoldsen E: Transcranial Doppler recordings in raised intracranial pressure. Acta Neurol Scand 87:488-493, 1993

16. Jensen RL, Hahn YS, Ciro E: Risk factors of intracranial pressure monitoring in children with fiberoptic devices: a critical review. Surg Neurol 47:16-22, 1997

17. Kochanek PM, Carney N, Adelson PD, Ashwal S, Bell MJ, Bratton S, et al: Guidelines for the acute medical management of severe traumatic brain injury in infants, children, and adolescents - second edition. Pediatr Crit Care Med 13 Suppl 1:S1-S82, 2012 (Erratum in Pediatric Crit Care Med 13:252)

18. Martin NA, Patwardhan RV, Alexander MJ, Africk CZ, Lee JH, Shalmon E, et al: Characterization of cerebral hemodynamic phases following severe head trauma: hypoperfusion, hyperemia, and vasospasm. J Neurosurg 87:9-19, 1997

19. McQuire JC, Sutcliffe JC, Coats TJ: Early changes in middle cerebral artery blood flow velocity after head injury. J Neurosurg 89:526-532, 1998

20. Melo JRT, Di Rocco F, Blanot S, Cuttaree H, Sainte-Rose C, Oliveira-Filho J, et al: Transcranial Doppler can predict intracranial hypertension in children with severe traumatic brain injuries. Childs Nerv Syst 27:979-984, 2011

21. Moreno JA, Mesalles E, Gener J, Tomasa A, Ley A, Roca $\mathrm{J}$, et al: Evaluating the outcome of severe head injury with transcranial Doppler ultrasonography. Neurosurg Focus 8(1):e8, 2000

22. Muizelaar JP, Marmarou A, DeSalles AA, Ward JD, Zimmerman RS, Li Z, et al: Cerebral blood flow and metabolism in severely head-injured children. Part 1: Relationship with GCS score, outcome, ICP, and PVI. J Neurosurg 71:63-71, 1989

23. Nagai H, Moritake K, Takaya M: Correlation between transcranial Doppler ultrasonography and regional cerebral blood flow in experimental intracranial hypertension. Stroke 28:603-608, 1997

24. Ojha BK, Jha DK, Kale SS, Mehta VS: Trans-cranial Doppler in severe head injury: evaluation of pattern of changes in cerebral blood flow velocity and its impact on outcome. Surg Neurol 64:174-179, 2005

25. Shapiro K, Marmarou A: Clinical applications of the pressure-volume index in treatment of pediatric head injuries. J Neurosurg 56:819-825, 1982

26. Sharples PM, Stuart AG, Matthews DSF, Aynsley-Green A, Eyre JA: Cerebral blood flow and metabolism in children with severe head injury. Part 1: Relation to age, Glasgow coma score, outcome, intracranial pressure, and time after injury. J Neurol Neurosurg Psychiatry 58:145-152, 1995

27. Trabold F, Meyer PG, Blanot S, Carli PA, Orliaguet GA: The prognostic value of transcranial Doppler studies in children with moderate and severe head injury. Intensive Care Med 30:108-112, 2004

28. van Santbrink H, Schouten JW, Steyerberg EW, Avezaat CJ, Maas AI: Serial transcranial Doppler measurements in traumatic brain injury with special focus on the early posttraumatic period. Acta Neurochir (Wien) 144:1141-1149, 2002

29. Voulgaris SG, Partheni M, Kaliora H, Haftouras N, Pessach IS, Polyzoidis KS: Early cerebral monitoring using the transcranial Doppler pulsatility index in patients with severe brain trauma. Med Sci Monit 11:CR49-CR52, 2005

30. Zierski J: Blood flow in brain structures during increased ICP. Acta Neurochir Suppl (Wien) 40:95-116, 1987

31. Zweifel C, Czosnyka M, Carrera E, de Riva N, Pickard JD, Smielewski P: Reliability of the blood flow velocity pulsatility index for assessment of intracranial and cerebral perfusion pressures in head-injured patients. Neurosurgery 71:853-861, 2012

32. Zwienenberg M, Muizelaar JP: Severe pediatric head injury: the role of hyperemia revisited. J Neurotrauma 16:937-943, 1999

\section{Author Contribution}

Conception and design: all authors. Acquisition of data: all authors. Analysis and interpretation of data: O'Brien. Drafting the article: all authors. Critically revising the article: all authors. Reviewed submitted version of manuscript: O'Brien. Approved the final version of the manuscript on behalf of all authors: O'Brien. Statistical analysis: O’Brien. Study supervision: O’Brien.

\section{Correspondence}

Nicole Fortier O'Brien, Division of Critical Care Medicine, Department of Pediatrics, Nationwide Children's Hospital, The Ohio State University, 700 Children's Dr., ED-350, Columbus, OH 43205. email: nicole.obrien@ nationwidechildrens.org. 